\title{
Interruption as a reflection of speaker's identity in the 2020 US presidential debates
}

\begin{abstract}
The article establishes the role of interruption as a key communicative strategy which defined the character of the 2020 US presidential debates. It is posited that the participants of the debates, namely Donald Trump and Joseph Biden, realized how effective certain types of linguistic behavior could be and deliberately used specific communicative tactics to achieve better results and win the voters' support. Some of the strategies that the participants resorted to were merely situational; however, most of the strategies identified in the research had a recurrent nature representing the debating styles of the politicians. It is also assumed in the study that repeated breaches of a normal turn-taking process such as systemic interruptions have the potential to modify the public perception of the politician's communicative styles, which are seen in the paper as inherent components of the politicians' identities.
\end{abstract}

\section{Introduction}

Research across many domains has shown that particular identity categories and specific linguistic devices and resources are tightly interconnected. Communication studies understand social identity of a speaker as a multi-level structure incorporating the features of the objective world, such as the age, gender, and accent of the speaker reflected in the physical acoustic parameters of their voice (Creel and Bregman 2011); elements of perception, cognition and preferred ideology objectified in a discourse with the help of conceptual thinking (Van Dijk 2010); and features of a speaker's self-expression realized in speech through assumed membership (Antaki, Condor, and Levine 1996).

This communication-centered concept of identity increasingly moves beyond the idea that identity categories simply determine the speaker's language, suggesting that language means, in their turn, can be actively deployed to produce new identities. We assume, therefore, that it might be of great analytic value to ap- 
proach identity as a relational phenomenon that "emerges and circulates in local discourse contexts of interaction" (Bucholtz and Hall 2005: 586) rather than as a stable structure located primarily in the individual's psyche.

This way, the development of a speaker's identity can be viewed from the perspective of newly accepted conversational patterns, models of speech maneuvering, and methods of achieving a communicative goal. However, it is evident that identity change can be neither rapid nor radical. A speaker cannot instantly change the multi-level identity construct because, if possible, the idea of a solid identity structure might run a risk of immediate disintegration.

Identity theories vary in their assessment of the plasticity of identifications. For example, while acknowledging the situational flexibility of social identities, Howard (2000) nevertheless prefers to emphasize their relatively enduring nature. At the same time, the communicative aspect of a speaker's identity, by which we understand a set of rhetorical techniques typically used by the speaker to project their ideas in oral discourse, looks more susceptible to the change.

We know that communicative goals may be achieved through a number of means, and rhetoric strategies are about the choice that helps people fulfill their objectives. Van Dijk (2010) calls such choices the situational "applications of social identities" that can modify an existing speaker's identity or contribute to constructing a completely new one.

In the present paper, we intend to analyze these "performances of identity" (Van Dijk 2010) in the context of election debates since this genre of political discourse explicitly reflects the times, dominant ideology, cultural shifts, political leanings of the general population of a country, and tends to change with time.

To fit into this paradigm, politicians often have to modify certain aspects of their identity (communicative roles and rhetorical style, in particular) and demonstrate flexibility in the use of self-categories to suit the specific tastes of the electorate (TV viewers). They also use their modified identities as "warrants or authority for a variety of claims they make and challenge, and the identities they invoke change as they are deployed to meet changing conversational demands" (Antaki, Condor, and Levine 1996: 473).

The rationale for choosing 2020 Trump - Biden debates for analysis was that immediately after their completion, political experts and analysts in the USA made multiple claims that the excessive use of interruptions in the 2020 presidential debates reportedly affected the public perception of the participating politicians ${ }^{1}$.

1 With Cross Talk, Lies and Mockery, Trump Tramples Decorum in Debate With Biden, available at: https:// www.nytimes.com/2020/09/29/us/politics/trump-biden-debate.html (Date of access: 20.11.21); Interruptions and Insults: All About the Very Uncivil Tone of the First Presidential Debate, available at: https:// time.com/5894565/interruptions-insults-presidential-debate/ (Date of access: 20.11.21); Trump's Interruptions Had a Double Message, available at: https://www.theatlantic.com/culture/archive/2020/09/uglyfamiliarity-trump-debate-interruptions/616547/ (Date of access: 20.11.21); Op-Ed: The Trouble with Counting Interruptions in a Debate, available at: https:/www.latimes.com/opinion/story/2020-10-20/ donald-trump-joe-biden-debate-interruptions (Date of access: 20.11.21). 
With not so many papers having attempted to use debate interruptions as a feature affecting the speaker's identity, we decided to investigate the potential effect that deviations from the standard turn-taking procedure could have on perceiving the speaker's personality.

The aim of the intended study was to analyze the role of interruptions in the debates and assess their influence on the communicative styles of the two politicians engaged in the debates, namely Donald Trump and Joe Biden.

In this study, we also intend to provide details of specific practices of overlaps and interruptions undertaken by the speakers through which their communicative identities are proposed, adjusted, and managed. By analyzing these micromoments of identity construction, we also attempt to pinpoint specific occasions where particular identity issues become salient to the TV viewers of the debates.

\section{Related Work}

\subsection{Role of Interruptions in Talk-in-interaction}

The research tradition has contributed a considerable amount of study to the various factors involved in turn-taking. According to one of the main postulates of CA, natural speech is strictly ordered. Any naturally occurring talk-in-interaction has a specific axis, the basis of its order. Sacks, Schegloff, and Jefferson (1974) proposed that turns in a conversation are made up of "turn-constructional units" or TCUs. The end of any TCU represents a so-called "transition-relevance place" or TRP, which is a point when a next speaker may attempt to start a new turn.

An interruption in its basic form is viewed in CA as a start outside the TRP and, therefore, regarded as a violation of the existing order. The early CA perceived such interruptions as problematic for both speakers and disruptive for the intercourse, suggesting the existence of several repair mechanisms meant to restore the regular order.

Later research, however, doubted the existence of specific turn-taking conventions and explained the conversational sequencing by "general pragmatic principles of efficiency and consideration for others" (Power and Dal Martello 1986: 39). Similarly, O'Connell, Kowal, and Kaltenbacher (1990) stated that there is no structural pattern of turn-taking that is either correct or faulty, normal or pathological; "kinesics, prosody, content, knowledge, and attitude of the interlocutors about the topic, about one another, and about the situation - all these situational elements can change the direction and pace of turn-taking from moment to moment" (O'Connell, Kowal, and Kaltenbacher 1990: 360).

The concept of interruption evolved accordingly. Orestrom (1983), for instance, emphasized that situational context and interlocutors' intentions directly affect the occurrence of interruptions. He believes that even if interlocutors repeatedly interrupt each other, the communicative purpose of the conversation is not necessarily interfered with. In contrast to the original CA concept, which viewed 
overlaps and interruptions as disruptions, Goldberg (1990) shows that many of them are supportive in nature and are sometimes "expected" by the speaker.

Oertel et al. (2012) believe the duration of the overlaps to be a defining feature when classifying their competitive or cooperative nature. The authors state that non-competitive overlaps tend to be relatively short and are resolved soon after the second speaker has recognized them. Competitive overlaps ("interruptions"), on the other hand, are typically longer and more persistent because speakers keep on speaking despite overlapping.

At the same time, Gravano and Hirschberg (2012) suggest that the competitive nature of overlaps is connected with the place of an intervention in the turn where it occurs. "Interruptions" are most likely to occur before the completion of intonational phrase units (IPUs), disrupting the meaning of the whole turn. In contrast, "overlaps" happen right after the completion of an IPU or on its final syllables, which does not significantly affect the meaning or the structure of the turn.

The existing consensus about the classification of interruptions in the studies of both institutional (Shaw 2000) and mostly non-institutional spoken discourse (Goldberg 1990; Gravano and Hirschberg 2012; Heldner and Edlund 2010; Oertel et al. 2012), which we share in this paper, is that their character (cooperative/ supportive/ competitive/ conflicting) is mostly context-oriented and depends on the speakers' communicative intentions. Following Chowdhury et al. (2019), and mainly to facilitate further data analysis, we suggest dividing all interruptions into two large groups of "competitive overlaps" (CO) and "non-competitive" overlaps (NCO) with some distinctive subcategories typifying both types and important for the present study (Table 1).

\begin{tabular}{|l|l|}
\hline Competitive overlaps (CO) & Non-competitive overlaps (NCO) \\
\hline interruptions & proper overlaps \\
\hline simultaneous starts & backchannels \\
\hline
\end{tabular}

Table 1. Classification of overlaps after Chowdhury et al. (2019) adapted for this study

In this study, COs are defined as scenarios when (a) an intervening speaker starts a new turn outside the TRP, before the completion of the current speaker's turn ("interruptions") or (b) at a TRP ("simultaneous starts") and both speakers display interest in holding the turn for themselves. Whereas NCOs comprise situations when (a) a speaker mistakenly starts a turn near a possible completion of the ongoing turn ("proper overlaps"), with the current speaker showing no intention of keeping the turn; and (b) "backchannels," defined as "certain brief, spontaneous reactions from the listener, signaling continued attention, agreement, and various emotional reactions" (Orestrom 1983), but not aimed at keeping the turn.

We admit that this division of overlaps is not too elaborate to include all the possible variations of turn types, but, at the same time, it is simple enough for the 
auditors/annotators doing practical research in spoken discourse to classify the most frequent overlapping turns. Most importantly for us, it includes the factor of the speaker's communicative intention, which is fundamental for this study.

Decoding the communicative intentions of the speaker is based on the multiple pragmatic theories of utterance which establish the role of extralinguistic factors and situational context in speech interpretation. The speaker's meaning is usually interpreted as "a complex mental state involving a series of nested intentions" (Wilson 2019), with them being immediately transparent to the listener through a conversation scenario.

Although pragmatic theories do not establish a direct correlation between communicative intentions and interruptions, they demonstrate that a speaker often chooses a certain type of "overtly intentional communication" (and presumably a turn-taking mode) suitable to realize that intention or at least "make it clear to the audience that [the speaker] has one" (Wilson 2019:3). In this way, there is a fundamental difference in the messages that $\mathrm{CO}$ and $\mathrm{NCO}$ s bring to the listener.

Concerning the quantitative measurements of overlaps, computer studies of conversations state that "about $40 \%$ of all between-speaker intervals in a normal conversation are overlapped in one way or another" (Heldner and Edlund 2010: 564). However, computer methods of speech segmentation do not allow differentiating between types of overlaps, nor do they consider the cooperative/competitive nature of these interruptions. As a result, the numbers of overlaps obtained by the automated speech analysis are typically somewhat higher than the counts done in the auditory analysis of interruptions because the auditors do not consider technical overlaps as problematic for turn-taking and exclude them from their counts (Schegloff 2000).

\subsection{Role of Interruptions in a Debate}

In terms of the discourse types, it is generally accepted that all forms of institutional interaction (including debate) can be characterized by a "systematic reduction or specialization of the array of practices observable in ordinary conversation" (Hutchby 2019: 4). In such a view, the numbers of competitive and non-competitive overlaps undertaken by the participants of political debates are expected to be somewhat different from ordinary conversations, emphasizing how interruptions and interruption strategies help the interlocutors achieve their communicative goals. The ultimate criterion for the success of such interaction is not the smooth interchange of speaking turns but the fulfillment of the purposes determined by the institutional setting.

The framework and the agenda of presidential debates in the USA, including the televised format, the harsh competition for swinging votes, and the subsequent polarization of the society, definitely makes this kind of political interaction a specific discourse genre. However, "in the near-complete absence of any comparative work" explained by the fact that "debate research remains very US-centric" 
(Anstead 2016: 510), it would be advantageous for our paper to use some conclusions made in the studies of parliamentary debates, which, being equally "formal and adversarial in style" (Shaw 2000), seem to be a relevant subject for comparison. Though country and culture specific, parliamentary debate is similar to the presidential debate in that "the debate floor is sought after for both political and professional gain" (Shaw 2000: 401).

Although turn-taking sequences in parliamentary and presidential debates are rule-regulated, they just as well allow for spontaneity and unpredictability. The studies of the parliamentary debate show that institutional constraints always parallel the turn-taking structure of parliamentary interaction. "Conventional turntaking in the debate represents a challenge for speakers, who, on the one hand, are expected to comply with institutional norms (the debate rules) and, on the other, try to impose their stances and achieve goals at the cost of violating those rules" (Ilie 2015: 8). Therefore, it is believed that it is precisely the norm deviations, rule violations, and verbal disruptions that can most clearly reveal various particularities of speakers' identities in a debate through verbal and nonverbal expressions of interpersonal arguments.

To make co-performing in the debate more explicit for analysis, Van Dijk (2004) suggested viewing the participants of the debates in terms of different kinds of their roles: their social roles (e.g., based on gender, class, ethnicity, profession, organization, etc.), interaction roles (friend, enemy, opponent, etc.), and their communicative roles (various producer and recipient roles). All these roles come into play at the same time in the institutional setting when, for instance, "the traditional speaker/recipient role distinction obviously controls the system of turntaking" (Van Dijk 2004: 359), making certain aspects of the politician's personality especially noticeable in the changing political context.

We believe that the assumed communicative roles, also known as "performances of identity" (Van Dijk 2010), are realized in the debate through rhetorically structured communicative and metadiscoursal strategies used by the speakers to signal, highlight, mitigate, or cancel parts of their ongoing performance. These strategies include various manifestations of the participants' cognitive and interpretational acts aimed at controlling, evaluating, adjusting, and negotiating the goals and the effects of their and their interlocutors' ongoing talk. However, how these identity shifts may affect the audiences' long-term perception of a politician's identity remains to be further investigated.

The 2000 Bush-Gore presidential debate studies demonstrated noticeable effects of watching presidential debates on the public perception of politicians' identities. The pre/post-test methodology of the study provided evidence that Bush significantly "enhanced perceptions of his character (but not of his policy positions), while Gore improved perceptions of his policy positions (but not of his character)" (Benoit, McKinney, and Holbert 2001). The data also revealed that the 
debates increased the confidence of vote choices for those who did not change their preferred candidate throughout the study.

After a major change in the US presidential debate format in 2008, which permitted direct exchange between the candidates, this institutional interaction became even closer to the traditional parliamentary debates allowing for overt confrontation, rebuttal, and even verbal clashes.

The studies of 2012 Republican presidential primary debates in the USA discovered that a candidate's power at the time of a debate directly correlated with the structure of interactions, such as turn frequency and interruption patterns (Prabhakaran, John, and Seligmann 2013). Researchers prove that the interruptions in the debate reflect, on the one hand, the speaker's proactive or reactive disposition and, on the other hand, the participants' strong competitive spirit. What is more, the power of a candidate is not seen in the debate as a given value but fluctuates in the course of the debate.

Although research into non-institutional talk, as we stated earlier, proved that interruptions are not always meant to disrupt the turn-taking but can be signs of support and co-performance, Jacobsen's (2019) studies of the US 2016 Presidential debates, as an example of institutional interaction, give empirical evidence of the fact that the viewers, as well as the participants of the debates, predominantly associate interruptions with arguments. The direct exchanges occurring in the debate are predominantly seen as confrontation because the candidates not only "orient to conflicting prior discourses but also attempt to portray each other's talk as divergent by recontextualizing it" (Jacobsen 2019: 82).

The case study of communicative strategies in the 2016 Clinton-Trump debate demonstrated a high potential of interruptions and backchannels in defining the winner of the debate (though not the winner of the elections) as the participants consider this form of interaction to be a way of presenting and most importantly, personifying their political program (Tymbay 2018: 120). The communication strategies of Trump and Clinton were so opposed in the final presidential debate that they eventually began to complement each other. Trump's critical backchannels perfectly fitted Clinton's desire to keep the turn, thus demonstrating a compromise between institutional norms and the self-imposed communicative identity.

Interestingly enough, the 2020 US Presidential debate witnessed a new change of rules, which happened right between the first and the second debate ${ }^{2}$. The microphones of the participants were supposed to be muted unless they had open discussion time. In contrast to the 2008 changes, which were meant to transform the debate into a more spontaneous discussion, the new procedure was supposed to limit the direct exchange, reduce the candidates' ability to interrupt each other, and

2 The first debate took place on September 29, 2020. The next debate was scheduled on October 15 but was later canceled due to Trump's COVID-19 diagnosis and his refusal to appear remotely rather than in person. As a result, the second (and final) debate took place on October 22. 
create a calmer debate with more room for discussion of political matters. However, analysts later concluded that "norm-breaking" and "theft of the speaking time" remained inherent features of the second debate, with "the contentious crosstalk between the two candidates and the moderator [making] long sections of the candidates' first debate nearly impossible to hear or follow" (Stewart 2020).

\section{Material and Methods}

The research data set included two debates: the first 2020 presidential debate (available at: https://www.youtube.com/watch?v=Y4HQzeI8F_U, from 0:00 to 1:33:27. Date of access: 20.11.21) and the second 2020 presidential debate (available at: https://www.youtube.com/watch?v=m53kMTYeOak, from 3:30 to 1:36:30. Date of access: 20.11.21).

Since the material for analysis consisted of only two publicly accessible video recordings of the presidential debates between Joe Biden and Donald Trump, a case study methodology implying a quantitative and a thorough qualitative observation of the data was chosen as most suitable for our purposes. The two-stage analysis of turn-taking in the 2020 US presidential debates was conducted to meet the following research objectives:

- to identify the character and the dominant types of interruptions in the debates;

- to define the status and the role of interruptions along the cooperation/ confrontation line;

- to establish the relationship between the interruptions and communicative strategies chosen by the speakers;

- to assess the overall effect of interruption strategy on the speakers' identities.

The present study involves a variety of methods. We assume that the proper analysis of interruption strategies in the debates should combine the terminology and methodology of conversation analysis (CA) and the approach and interpretation techniques of discourse analysis (DA).

Although providing enough apparatus for the description and the systemic presentation of the talk-in-interaction procedure, CA seems to be limited in tools for linking separate conversational practices with the communicative and psychological characteristics of the speakers. At the same time, DA allows for this because it considers communicative roles and assumed identities of the speakers to be discursive products created or refined at the time of the talk rather than ontologically given characteristics of the interlocutors. DAalso suggests that speakers have complete control over the situation and can choose the communicative tools they employ.

The CA concept of the immediate "local context" (Sacks, Schegloff, and Jefferson 1974: 700) also loses its value when going beyond the analysis of "adjacency pairs," that is, two contextually united subsequent turns. When it is necessary to explain the motivation of repeated interruptions or the strategic change in the 
discourse tactics, the analyst has to look at longer discourse sections and view the "contextual implications," that is "conclusions deducible from the input and the context together, but from neither input nor context alone" (Wilson and Sperber 2004: 609). This way, DA "not only captures something important about the social world, but also plays a key ethical and political role in showing how social phenomena are discursively constituted: it demonstrates how things come to be as they are, that they could be different, and thereby that they can be changed" (Hammersley 2003: 758).

The first stage of the study consisted of a quantitative auditory analysis of the debates' video recordings with a total duration of 3 hours 10 minutes. It was conducted with the help of a group of four MA majors in English Language and Literature at the FP of the TUL University (The Czech Republic). All the auditors were non-native speakers (with a $\mathrm{C} 1 / 2$ level of English) interested in different aspects of Phonetics and Pragmatics for their future diploma papers. They kindly agreed to watch and listen to the debates twice and fill in the research protocols.

First, the video recordings were approached with the CA terms and methodology to identify the "study units" and "sampling units." A study unit was defined as an overlap of two subsequent turns. Each study unit was supposed to be marked as such by at least three of the four auditors for reliability purposes. The total (mean) number of the study units identified in the debates was 433 , with a standard deviation $(\mathrm{SD})=6.2$.

The auditors' verbal protocols included counting the total number of turns, identifying the types of the turns during the first viewing and listening and counting the number of turns initiated by each participant separately during the second viewing and listening.

Before the first listening session, the auditors were instructed about the turn types. To simplify the task of the auditors, we reduced the categories of turns widely used in the CA to just five options with the following definitions (elaborated by us for this particular case study):

- "smooth transition" (a change of the speaker conducted without a long pause or an overlap);

- "overlap" (a technical overlap of turns without significant disruptions to the communication process);

- "interruption" (a change of the speaker happening in the middle of the other speaker's turn, usually disrupting normal turn-taking);

- "crosstalk time" (quick periods of simultaneous speaking by both participants, when it is difficult to identify the dominant speaker);

— "backchannel" (short comments expressing agreement or disagreement).

The results of normalized counts obtained after the first stage of the analysis the mean numbers and standard deviations (SD) - are presented below in Table 2.

During the second viewing and listening, the auditors were also asked to mark the periods in the debates that they would classify as "communicative fight" epi- 
sodes. A "communicative fight" episode, also referred to as a "clash" (Jacobsen ${ }^{3}$ 2019), was defined by us as a series of interrupted turns where the persistent communicative intention of the interlocutor to take the floor was violently confronted by the present speaker.

The total (mean) number of communicative fight episodes, which later served as the sampling units of the study, identified by the auditors was 52 in the first debate and 17 in the second debate $(\mathrm{SD}=3)$. Special attention of the auditors during the second listening and viewing was drawn to marking the onsets of the communicative fight episodes. They were allowed to pause the video and mark the time of the onset to further normalize the counts. The auditors were also encouraged to make notes and comments if something, in their opinion, disrupted the normal flow of the debate procedure at these particular episodes. The "sampling units" marked by the auditors served as the material for the second stage of the analysis.

The second stage of the analysis, the qualitative content analysis of the sampling units (69 units, with the total duration of approximately $25 \mathrm{~min}$. or 13\% of all time of the debates), was based on the principles of DA, which assume that to realize the full potential of the discourse, it is necessary to view it at different levels.

To facilitate this stage, we used the annotations of the debates from the Transcription library available at https://www.rev.com/. The transcripts containing the exact timing of the turns made it possible for us to relate the times of communicative fight episodes, which were marked at the previous stage of the auditory analysis, to the annotations of the exact turns.

Structural analysis of the sampling units allowed us to detect the influence of separate structural units (turns, TRPs) on the general communicative semantics. The presuppositional analysis detected the underlying implicatures and logical connections within the sampling units. Elements of the cognitive analysis, namely the insight into the "relevance theory," which underlines the ability of the speaker to produce a cognitive stimulus "which is likely to attract your attention, to prompt the retrieval of certain contextual assumptions and to point you towards an intended conclusion" (Wilson and Sperber 2004:614), revealed the intentions of the interlocutors and the pragmatic characteristics of the turns, which remained implicit in the discourse.

Before presenting the study results though, it should be mentioned that the present case study had several limitations that must be taken into account. First of all, since we do not yet include into the research data set the recorded samples of the same politicians conversing in a different setting, it is too early to say to what extent the debate format de facto affected their communicative identities. What is more, the choice of sampling units for the second stage of the analysis was based on

3 Ronald Jacobsen's study “Interruptions and co-construction in the first 2016 Trump-Clinton US presidential debate" (2019) is particularly important for this paper as it inspects the interruption mechanisms the American politicians, namely D. Trump and H. Clinton, employed in the previous cycle of US election debates. The observation of D. Trump in both events (2016 and 2020) allows for adding a diachronic perspective to the current study of his communicative style. 
the perceptional opinion of the auditors, non-native speakers ${ }^{4}$, who had marked specific episodes as "communicative fights" and, therefore, might be viewed as subjective. Next, our conclusions about the use of interruption strategies remain largely hypothetical and may seem insufficient for generalizations as they are based on the observation of just two particular debates. Finally, the study did not include a pre/post-test of viewers' perception of the candidates' policies and personalities, which we believe to be a severe limitation that can be compensated for by further research.

\section{Analysis and Discussion}

In the following chapter, we would like to present our observations concerning the typology of turns and the character of interruptions found in the episodes of "communicative fights." The data supporting the analysis are presented in Tables 2 and 3.

\begin{tabular}{|l|l|l|}
\hline & First debate & Second debate \\
\hline Number of Turns (SD) & $793(6,2)$ & $526(4)$ \\
\hline Smooth Transitions (\%, raw) & $61 \%(486)$ & $76 \%(402)$ \\
\hline Interruptions (\%, raw) & $19 \%(154)$ & $13 \%(69)$ \\
\hline Backchannels (\%, raw) & $10 \%(80)$ & $6 \%(32)$ \\
\hline Crosstalk (\%, raw) & $9 \%(73)$ & $5 \%(25)$ \\
\hline
\end{tabular}

Table 2. Frequency of turn types

The quantitative data on the frequency of turn types obtained at the first stage of the analysis (Table 2) demonstrates a noticeable difference in the number of turns taken in the two debates for relatively the same time (approx. 93 min. each). The second debate saw a nearly $35 \%$ decrease in this number, which can partly be explained by the change of the rules of the debate.

The new rules naturally led to a higher number of smooth transitions, which increased from $61 \%$ to $76 \%$ respectively, and, consequently, to a falling number of interruptions and crosstalk time in the second debate. On the other hand, after the open criticism of their debating style in the media ("President Trump and Joe Biden faced off in a chaotic debate that devolved into an unrelenting volley of personal attacks and interruptions" (Macaya et al. 2020)), both politicians or rather their campaign managers may have realized that a high number of interruptions could damage the image of the candidates and recommend changing the strategies.

4 It should be noted though that research has indicated only a limited number of false matches (no more than $20 \%$ ) in the practice of non-native auditors of English speech (Potapov and Potapova 2006: 277), with general assessments of the group's performance in linguistic experiments being rather positive. 
As a result, the auditors recorded a three-fold decrease in the "communicative fight" episodes in the second debate. Despite this, the comparative analysis of the data from the two debates shows that the communicative styles of the participants did not change significantly (the number of interruptions and backchannels remained relatively high), which, in our opinion, reflects the intensity of competition and the span of the communicative fight.

The results of the second stage of the analysis are presented below with the help of descriptive methodology, by which we mean research techniques that allow moving from particular observations to generalizations. The study of the sampling units was focused on analyzing the differences in turn-taking modes of Donald Trump and Joe Biden, with specific attention paid to identifying repeated communicative techniques employed by the speakers.

\subsection{Interruption Strategy}

A remarkable feature which makes interruptions in the sampling units of the study different from spontaneous interruptions of a regular conversation is their recurring nature. Repeated interruptions, typically meant to "recontextualize a candidate's prior attacks" (Jacobsen 2019: 79), are defined in this paper as interruption strategies.

The following abstract (Example 1) demonstrates a combination of a proper overlap [discredited... By who], followed by a regular competitive interruption [And you can...The Media] in one "clash." Trump first attempted to take a turn on the final syllables of Biden's word "discredited," which was pronounced with a nuclear tone and thus perceived by the listeners as the closure of a TCU (and a TRP). That is why Trump's intrusion "By who?", though technically an overlap, at this point did not sound like a breach of the ordinary course of the discussion and the standard turn-taking rules.

Nevertheless, to finish his idea, Trump initiated a new turn and intervened again. This time he started his turn "The media" before any semantic center of the potential TCU was said by Biden, which was already perceived by the auditors as a competitive interruption. In the end, Biden managed to finish the sentence and prove his point. However, Trump, with his interruption strategy, seems to have put the credibility of Biden's words into question:

(1) Joe Biden:(23:11) He doesn't want tolet me answer because he knows I have the truth. His position has been totally, thoroughly discredited...

Donald Trump: (23:20) By who?

Joe Biden: (23:20) Andyou can...

Donald Trump: (23:20) The media.

Joe Biden: (23:20)...by everybody. Well, by the media, by our allies.

In the following example (Example 2), the interruption strategy was used by both participants of the debate simultaneously. Trump interrupted Biden in the 
middle of his utterance (in the middle of TCU). To keep the turn, Biden tried to repeat his words "by the way" several times as if interrupting Trump but failed to start a new turn. Eventually, Trump managed to take the turn, gain the initiative, and make the final statement.

(2) Joe Biden: (02:36) Yes. Well, that's what he's going to try to do, but there are thousands of scientists out there, like here at this great hospital, that don't work for him. Their job doesn't depend on him. They're the people... And by the way... Donald Trump: (02:51) We spoke to the scientists that are in charge... Joe Biden: (02:53) By the way... Donald Trump:(02:53) ... they will have the vaccine very soon.

A similar situation can be observed in the following case (Example 3), with a slight difference: Trump was even more effective in keeping the speech initiative. Biden, at some point, tried to interrupt Trump and at a TRP started a new turn contextually meant to defend his political reputation, but Trump increased the speed and the volume of his speech, kept his turn and finished his idea.

(3) Donald Trump: (03:44) Because you know what? There's nothing smart about you, Joe. Forty-seven years you've done nothing. Joe Biden: (03:49) Well, let's have this debate...

Donald Trump: (03:51) Let me just tell you something, Joe. If you would have had the charge of what I was put through, I had to close the greatest economy of the history of our country. And by the way, now it's being built again, and it's going up fast.

In the first debate, Trump started $8 \%$ more turns than Biden and $12 \%$ in the second one (Table 3 ). He also interrupted his partner more often (roughly 130 times in both debates vs. 60 interruptions by Biden). Interruptions (and interruption as a strategy in particular) served Donald Trump just right in a bid to make a short political statement and stop the opponent from expressing the point of view he disagreed with, similarly to his debates with H. Clinton in 2016 (Jacobsen 2019; Tymbay 2018).

In the following example (Example 4), Trump intervened into the turn to prevent Biden from saying some unpleasant facts about people from Trump's administration:

(4) Joe Biden: (23:48) Well, I'll give you the list of the people who... Donald Trump: (23:50) I'll fire them.

In the case below (Example 5), Trump interrupted Biden again to question his stance on the US legal system and make the audience cast some doubt on Biden's claims:

(5) Joe Biden: (35:12) I'm in favor oflaw. You... [crosstalk]. Donald Trump: (35:14) Are you in favor oflaw and order? 


\subsection{Critical Backchannels}

Earlier studies of Trump's debating strategies classified a significant part of his interruptions as "bracketing interjections" (Jacobsen 2019) or "negative backchannels" (Tymbay 2018), considering them to be a defining type of his speech behavior. In the course of the debates, Trump quite repeatedly makes critical comments on the opponent's words without expressing his intention to take a regular turn, hence, to classify them we use the term "backchannel" following Orestrom (1983). These comments may be left unnoticed by the current speaker or cause a loss of concentration, which, very likely, leads to a change of the whole topic discussed.

In the following case (Example 6), for instance, Biden intended to speak about Trump's professional limitations. In contrast, after Trump's interruption (a critical backchannel), he was forced to abandon this topic and switch to his plans for the future:

(6) JoeBiden:(14:17) All he knows is how to do ... Donald Trump:(14:18) On Super Tuesday, you got verylucky. Joe Biden:(14:21) I got verylucky. I'm going to get verylucky tonight as well.

Understanding the nature of these backchannels (bracketing interjections) is particularly important for this study because the features of backchannels can be found in many interrupting turns, especially those made by Trump. They have a brisk character and usually consist of no more than several words.

\subsection{Direct Address Strategy}

At a certain point of the first debate, when the number of Donald Trump's interruptions and backchannels started to dominate the course of the debate, Joe Biden got involved in the "interruption game" too and tried to use a similar strategy against Trump (Example 7):

(7) Donald Trump:(24:02) Hey, let me just tell you, Joe... Joe Biden:(24:03) No, no. Mr. President... [crosstalk] Donald Trump: (24:04) Three and a half million, [Joe... Joe Biden: (24:06) That] is simply not true.

Biden's interruptions though are a bit different. They are more directed at the audience than Trump's. Biden looks at the camera rather than his opponent and does not expect any reaction from Trump, which allows classifying many of his turns as a "direct address strategy," a term that we have coined to emphasize his aiming the message directly at the TV viewer, not the collocutor in the debate.

At the same time, Biden's interruptions are somewhat similar to Trump's backchannels. By using them, Biden seems to sum up what is happening in the debate room. He makes comments for the audience to understand what is being said by the opponent. He addresses his electorate directly without responding to Trump's words (Example 8): 
(8) Donald Trump: (24:47) Chris, can I be honest? It's a very important question... Joe Biden: (24:49) Try to be honest.

It should be noted that this particular way of interacting with the audience, using backchannels, quite predictably makes it challenging to count the actual number of turns in the debates (hence a high SD). On the one hand, Trump and Biden take turns the usual way. There are no overlaps or long pauses between the TCUs. On the other hand, there is no proper contact between the speakers. Their turns look like "jigsaw pieces" of monologues directed at the viewers. There are no communicative ties between the speakers, as if they are talking with the people on the other side of the TV screen but not with each other. In the following abstract (Example 9), for instance, there are four turns but no true turn-taking happening:

(9) Donald Trump: (15:41) No, I want to give them better healthcare at a much lower price because Obamacare is no good.

Joe Biden: (15:45) He doesn't know how. He doesn't know how to do that.

Donald Trump: (15:46) I've already fixed it.

Joe Biden: (15:47) He has never offered a plan.

The exchange above can be presented differently (the order of turns was deliberately changed) to prove the absence of real communication between Trump and Biden (Examples 9-a, 9-b):

(9-a) Donald Trump: No, I want to give them better healthcare at a much lower price because Obamacare is no good. I've already fixed it.

and

(9-b) Joe Biden: He doesn't know how. He doesn't know how to do that. He has never offered a plan.

Even with this order of turns, the communicative contact between the candidates is almost non-existent, which is supported by Biden's use of the pronoun "he" instead of a more appropriate "you." At this moment, as well as on many other similar occasions, Biden prefers to interact with the TV viewers (direct address) rather than his opponent, which again demonstrates the audience's presence as a meaningful participant in the debates.

\subsection{Emotional Appeals}

It was stated in earlier studies that emotional appeal to the audience is quite common in political discourse (Cislaru 2012). Such emotional appeals are partand-parcel of many rhetorical strategies. Power relations are formed through deliberate induction of emotional responses in the audience to affect judgments over the evidence, "skillful rhetoricians using the same evidence can sway audiences one way or another by engaging different emotions" (Dowding 2013: 17). 
It is difficult to say how much of the rhetorical coaching the participants of the 2020 debates had, but the examples of their emotional addresses to the audience are pretty evident in the discourse. Trump, for example, frequently makes emotional statements like "Well, then you know what, he's wrong!" (42:41) amidst communicative fight episodes.

The same is noticeable in Biden's behavior too. By repeating his statement, "People want to be safe," in the example below (Example 10), he appeals to the viewers' feelings but does not mean to take a turn (a direct address strategy). His backchannels are usually longer than Trump's and are typically more distinctly pronounced:

(10) Donald Trump: (14:03) No, people want their schools open. They don't want to be shut down. They don't want their state shut down. They want their restaurants. I look at New York. It's so sad what's happening in New York. It's almost like a ghost town, and I'm not sure it can ever recover what they've done to New York. People want their places open. They want to get back to their lives. Joe Biden: (14:19) People want to be safe.

Donald Trump: (14:20) They'll be careful, but they want their schools open. Joe Biden: (14:22) People want to be safe.

Donald Trump: (14:23) I'm the one that brought back football. By the way, I brought back Big Ten football. It was me, and I'm very happy to do it.

There are five consecutive phrases in Example 10, yet there is no actual turntaking again, as Biden's turns (14:19;14:22) are just emotional backchannels.

At multiple points, this lack of cooperation between the candidates even required the intervention of the host (Chris Wallace - first debate, Kristen Welker - second debate). In the following example (Example 11), Biden decided to stop the crosstalk after Wallace's words using his direct emotional address as a repair mechanism. He skillfully took the situation under control and expressed his dissatisfaction with the opponent by making a final statement which was again, like in the previous examples, aimed at the TV viewers in general rather than at Trump or Wallace in particular.

(11) Joe Biden: (14:41) God, I want to make sure...

Donald Trump:(14:42) You'd be...[crosstalk]

Chris Wallace: (14:43) Mr. President, can you let him finish, sir?

Joe Biden: (14:44) No, he doesn't know how to do that.

Donald Trump: (14:46) You'd be surprised. You'd be surprised. Go ahead, Joe. Joe Biden: (14:47) The wrong guy, the wrong night, at the wrong time.

\subsection{Us and Them Strategy}

Another feature of Biden's rhetorical style and presumably his communicative identity is the conscious use of the Us and Them opposition as a strategy to contrast 
himself and his party to Donald Trump (the Us and Them strategy). It is known that the opposition Us and Them is an integral part of the linguistic picture of society and American leaders, in particular, tend to use "the moralized lexical-grammatical resources to develop the semantic categories of Us and Them and contribute to the kind of ideological polarization" (Oddo 2011:308).

This conceptual opposition is reflected in the language and speech and synchronized with the philosophical categories of good/evil, good/bad, etc. Predominantly, "good" is associated with "own" while "bad" correlates with "alien." Thus, according to Biden (and due to the strategy), the voters, himself included, are presented as "us." In contrast, Trump belongs to the opposite end of the moral spectrum (Examples 12-a, 12-b):

(12-a) Joe Biden: (20:43) He told us what a great job Xi was doing. He said we owe him a debt of gratitude for being so transparent with us. And what did he do then? He then did nothing. He waited and waited and waited. He still doesn't have aplan.

Orlater:

(12-b) Joe Biden: (00:22) God. This is the same man who told you by Easter this would be gone away...

Biden ignores the questions of the opponent and addresses the audience (a "direct address strategy" again) with a call for action (Example 13), often accompanied by non-verbal signals typical of him: holding his both hands up with their edges turned to the camera as if framing the monitor:

(13) Donald Trump:(18:05) Are you going to pack the court? Joe Biden: (18:07) (looking at the camera) Vote now. Donald Trump: (18:08) Are you going to pack the court? Joe Biden: (18:09) (looking at the camera) Make sure you, in fact, know your senators.

Sometimes Biden's emotional remarks seem to be rather rude (Examples 14-a, 14-b, 14-c, 14-d):

(14-a) (addressing Trump) Will you shut up, man?

(14-b) (addressing the audience) Will he just shush for a minute?

(14-c) (addressing the audience) It's hard to say a word with this clown.

(14-d) (addressing Trump) You're the worst president America has ever had. Come on.

\subsection{Repetition Strategy}

Trump, as a rule, reacts to the rude or somewhat offensive passages directed at him by repeating short phrases irrespective of the turn-taking order (a "repetition strategy"). This feature of his, which was also attested in earlier papers (Jacobsen 
2019), is so common in the debates that it is viewed by us as another feature of his communicative style, manifesting how he exploits the "clip" mentality of the electorate.

Ruzhentseva (2017) defined the "clip" mentality as a "new cognitive style of information perception" evoked in the audiences (especially younger ones) by the non-linear presentation of information in the media. It is also believed that clip mentality determines a specific character of information consumption when the target internet audience better remembers short and sharp phrases (similar to video clips).

Trump's comments are indeed often brisk and sharp. When repeated, they become even more noticeable and thus better remembered. The repetitions (typically realized through backchannels) are not always meant to be responded to. They play a commentary role (Examples 15-a, 15-b) and just occasionally start a new turn (Example 15-c).

(15-a) Wrong...Wrong.

(15-b) That was said sarcastically, and you know that... That was said sarcastically.

(15-c) We've had no negative effect... We've had no negative effect, and we've had $35-40,000$ people at these rallies.

\subsection{Interplay of Strategies}

It is interesting how the different strategies identified in the sample units come into play simultaneously. In the abstract below (Example 16), Trump interrupted Biden, his usual way in the middle of a turn, outside the TRP (an interruption strategy). He repeated his short utterance several times (a repetition strategy). Biden reacted to this with a critical backchannel by addressing the audience directly (a direct address strategy):

(16) Joe Biden: (37:54) Look, what Isupport are the police having the opportunity to deal with the problems they face, and I'm totally opposed to defunding the police offices [...] And so we have to be...

Donald Trump: (38:35) That's not what they are talking about this. That's not what it is about. He's talking about defunding the police.

Joe Biden: (38:39) That is not true.

We have to say that such interplays of strategies were quite typical of the communicative fight episodes, which not only allows for various interpretations of the participants' strategic behavior, but also explains discrepancies and, as a result, a high standard deviation number $(S D=4.5)$ in the counts of turns initiated by each speaker separately Table 3 . 


\begin{tabular}{|l|l|l|}
\hline & First Debate & Second Debate \\
\hline Trump's turns (\%, raw) & $40 \%, 315$ & $38 \%, 200$ \\
\hline Biden's turns (\%, raw) & $32 \%, 251$ & $26 \%, 137$ \\
\hline The host's turns (\%, raw) & $28 \%, 226$ & $36 \%, 189$ \\
\hline
\end{tabular}

Table 3. Personal input of the participants

The data (mean numbers) show that in both debates Trump's overall turn impact was higher. In the second round, despite the rule change, he still started almost two-fifths of all turns. We explain this fact by his seemingly proactive stance in the debates, whereas Biden's role in both debates remained largely cautious and reactive. For instance, in his interaction with the hosts, Donald Trump was rather sharp and insistent, whereas Joe Biden was usually formal and polite.

\section{Conclusions}

As previous research shows, the role of an interruption as an instrument of rhetorical competition should not be underestimated. Interrupting a partner in an argument or a debate can be regarded as a communicative strategy of grabbing the floor or changing the course of the discussion.

The widely speculated breaches of the established protocol in the 2020 American presidential debates naturally aroused our research interest in the topic. Guided by the fact that "interruption" was a keyword in the public assessment of both debates, we decided to apply conversation and discourse analysis methodology to verify a hypothesis that the extensive use of "interruption strategy" may reflect communicative styles of the speakers. In examining "communicative fight" moments (treated in this study as "sampling units"), we hoped to reveal the effect that this mode of interaction has on identity construction.

The conducted analysis of the two presidential debates showed that, just as expected, interruption or rather a recurrent type of interruption dominated the debating procedure. Although the total number of various kinds of verbal intrusions, including backchannels and crosstalk periods, was entirely in line with previous studies (38\% in the first debate and even lower (24\%) in the second debate), the competitive character of these irregularities left the viewers with an impression that the candidates (Donald Trump in particular) incessantly interrupted each other.

In CA terms, a competitive overlap occurring outside a TRP was the dominant type of interruption identified in the debates. Since the auditors had to process a vast amount of recorded data (186 min.) and were primarily focused on identifying the "clashes" between the speakers, insignificant overlaps of turns of non-competitive nature, better visible in computer-assisted studies, were overlooked in the 
research. The second most common type of turns marked in the debates were backchannels ( $16 \%$ of all turns in both debates), most of which were critical rather than supportive. Finally, the category of crosstalk, which made up $14 \%$ of all turns, was seen in the research as a default choice of the auditor when they failed to classify the turn as an interruption or a backchannel because it was challenging to identify the dominant speaker/interrupter. We assume that this category partly includes simultaneous starts of the speakers and other possible subcategories of competitive overlaps, with most crosstalk happening during the "communicative fight" episodes or instead signaling them.

A recurring turn-taking model employed by the speaker throughout the debates was identified in the paper as a communicative strategy. The analysis of sampling units of the study, by which we mean the communicative fight episodes or "clashes" between the participants, showed that Donald Trump primarily resorted to a standard "interruption strategy," "critical backchannel" strategy, and "repetition" strategy, most of which, maybe under slightly different names, were already mentioned in earlier papers as his distinctive communicative characteristics. Joe Biden, in contrast, did not demonstrate the consistent application of an "interruption strategy" of any sort but repeatedly employed a "direct address" strategy, relating his passages straight to the TV viewers, thus vividly demonstrating the presence of the audience as a so-called "third" participant of the debates.

We believe that Trump's and Biden's communicative strategies identified in this paper contributed to the modification of the audience's perception of their identities; however, the true extent of this modification in the absence of a pre/ post perceptional test is hard to estimate.

A high number of turns started by Trump in the debates (including both regular "smooth" transitions in the question-answer sessions with the hosts and various interruptions during direct exchanges) portrays him as a pro-active speaker who is ready to "fight" for the turns. In contrast, Joe Biden's role in the debates was more reactive, with him initiating about $10 \%$ fewer turns than Trump.

Joe Biden seems to have been focused more on the content of his contributions paying less attention to their form. Another notable characteristic of his speaking style is the emotional appeal to the audience, for instance, repeatedly calling his loyal supporters for action or contrasting them to Trump's people in a Us and Them conceptual opposition.

Donald Trump's statements are generally shorter and more fragmented. His "repetition strategy," combined with "critical backchannels," is more oriented towards the "clip" mentality of internet audiences, as a result creating a fragmented and inconsistent portrait of his political agenda and of him as a speaker presenting it.

The span of communicative competition in the 2020 presidential debates was enormous, and we deem it was a combination of various factors, including the divergent communicative strategies of the speakers, the presence of the "third" participant (TV viewers), and the general political polarization of American society, 
that made interruption as a turn type so salient to the audience in the situational "applications" of identities of American politicians. The communicative fight episodes in the debates happened to be not only the clashes of turns but also the clashes of political opinions, that is why the viewers so closely associated what was said at these moments with how it was said.

By concluding the present analysis, it should be noted that although it is evident that televised debates provide incentives for politicians (or their campaign managers) to modify their speech behavior to pursue current political aims, it is still unclear to what extent and how fast they can do it. Studies have shown that speech in general and political discourse, in particular, can be an essential key to understanding a speaker's personality. The perception of the communicative and rhetorical style of the politician in a televised debate seems to be highly correlated with the public perception of the politician. Still, the actual relation between the speech strategies of the presidential candidates and their personalities or even election outcomes is yet to be established in further research.

\section{References}

Antaki, Charles, Condor, Susan, and Mark Levine (1996). Social identities in talk: Speakers' own orientations. British Journal of Social Psychology 35(4): 473-492, https://doi.org/10.1111/j.2044-8309.1996.tb01109.x

Anstead, Nick (2016). A different beast? Televised election debates in parliamentary democracies. The International Journal of Press/Politics 21(4): 508-526, https://doi.org/10.1177/1940161216649953

Benoit, William L., McKinney, Mitchell S., and Lance R. Holbert (2001). Beyond learning and persona: extending the scope of presidential debate effects. Communication Monographs 68(3): 259-273, https://doi.org/10.1080/03637750128060

Bucholtz, Mary, and Kira Hall (2005). Identity and interaction: a socio-cultural linguistic approach. Discourse Studies 7(4-5): 585-614, https://doi.org/10.1177/1461445605054407

Chowdhury, Shammur A., Stepanov, Evgeny A., Danieli, Morena, and Giuseppe Riccardi (2019). Automatic classification of speech overlaps: Feature representation and algorithms. Computer Speech \& Language 55: 145-167, https://doi.org/10.1016/j.csl.2018.12.001

Cislaru, Georgeta (2012). Emotions as a rhetorical tool in political discourse. Zaleska, Maria, ed. Rhetoric and Politics, Cambridge: Cambridge University Press, 107-126

Creel, Sarah C., and Micah R. Bregman (2011). How talker identity relates to language processing. Language and Linguistics Compass 5: 190-204, https://doi.org/10.1111/j.1749-818X.2011.00276.x

Dowding, Keith (2013). Emotional appeals in politics and deliberation. American Political Science Association 2013 Annual Meeting Paper. Available at SSRN:

https://ssrn.com/abstract=2301088 (Date of access: 10.10.21) 
Goldberg, Julia A. (1990). Interrupting the discourse on interruptions: An analysis in terms of relationally neutral, power-and rapport-oriented acts. Journal of Pragmatics 14 (6): 883-903, https://doi.org/10.1016/0378-2166(90)90045-F

Gravano, Agustin, and Julia Hirschberg (2012). A corpus-based study of interruptions in spoken dialogue. Interspeech 2012: 855-858, https://doi.org/10.21437/Interspeech.2012-193

Hammersley, Martyn (2003). Conversation analysis and discourse analysis: Methods or paradigms? Discourse \& Society 14(6): 751-781, https://doi.org/10.1177/09579265030146004

Heldner, Mattias, and Jens Edlund (2010). Pauses, gaps and overlaps in conversations. Journal of Phonetics 38(4): 555-568, https://doi.org/10.1016/j.wocn.2010.08.002

Howard, Judith A. (2000). Social psychology of identities. Annual Review of Sociology 26 (1): 367-393, https://doi.org/10.1146/annurev.soc.26.1.367

Hutchby, Ian (2019). Conversation analysis. Atkinson, Paul, Sara Delamont, Sara, Cernat, Alexandru, Sakshaug Joseph W., and Richard A. Williams, eds. SAGE Research Methods Foundations, 1-21, https://www.doi.org/10.4135/9781526421036789623

Ilie, Cornelia (2003). Discourse and metadiscourse in parliamentary debates. Journal of Language and Politics 2(1): 71-92, https://www.doi.org/10.1075/jlp.2.1.05ili

Ilie, Cornelia (2015). Parliamentary discourse. Tracy, Karen, ed. The International Encyclopedia of Language and Social Interaction. New York, NY: Jhon Wiley and Sons, https://www.doi.org/10.1002/9781118611463.wbielsi201

Jacobsen, Ronald R. (2019). Interruptions and co-construction in the first 2016 TrumpClinton US presidential debate. Journal of Pragmatics 148: 71-87, https://www.doi.org/10.1016/j.pragma.2019.05.019

Macaya, Melissa, Rocha, Veronica, Blaine, Kyle, and Jessica Estepa (2020). First 2020 presidential debate. CNN Politics. Available at:

https://edition.cnn.com/politics/live-news/presidential-debate-coverage-factcheck-09-29-20/index.html (Date of access: 10.10.21)

O'Connell, Daniel C., Kowal, Sabine, and Erika Kaltenbacher (1990). Turn-taking: A critical analysis of the research tradition. Journal of Psycholinguistic Research 19: 345-373, https://doi.org/10.1007/BF01068884

Oddo, John (2011). War legitimation discourse: Representing 'Us' and 'Them' in four US presidential addresses. Discourse \& Society 22(3): 287-314, https://doi.org/10.1177/0957926510395442

Oertel, Catharine, Włodarczak, Marcin, Tarasov, Alexey, Campbell, Nick, and Petra Wagner (2012). Context cues for classification of competitive and collaborative overlaps. Proceedings of the 6th International Conference on Speech Prosody. Available at: https://www.isca-speech.org/archive_v0/sp2012/papers/sp12_721.pdf (Date of access: 10.10.21)

Oreström, Bengt (1983). Turn-taking in English conversation. Lund, Sweden: Liber

Potapov, Vsevolod, and Rodmonga Potapova (2006). Jasyk, Rech, Lichnost [Language, Speech, Personality]. Moscow 
Power, Richard J. D. and Dal Martello, Maria F. (1986). Some criticisms of Sacks, Schegloff, and Jefferson on turn-taking. Semiotica 58 (1-2): 29-40, https://doi.org/10.1515/semi.1986.58.1-2.29

Prabhakaran, Vinodkumar, John, Ajita, and Dorée Seligmann (2013). Power dynamics in spoken interactions: A case study on 2012 republican primary debates. WWW 2013 Companion - Proceedings of the 22nd International Conference on World Wide Web. Available at: http://www2013.w3c.br/companion/p99.pdf (Date of access: 10.10.21)

Ruzhentseva, Natalia (2017). Clip mentality in the political discourse: Cognitive vector of the text adaptation. Voprosy Kognitivnoy Lingvistiki [Issues of Cognitive Linguistics] 4:90-103, https://doi.org/10.20916/1812-3228-2017-4-90-103

Sacks, Harvey, Schegloff, Emanuel A., and Gail Jefferson (1974). A simplest systematics for the organization of turn-taking for conversation. Language 50(4): 696-735, https://doi.org/10.2307/412243

Schegloff, Emanuel A. (2000). Overlapping talk and the organization of turn-taking for conversation. Language in Society 29(01): 1-63, https://doi.org/10.1017/s0047404500001019

Shaw, Sylvia (2000). Language, gender and floor apportionment in political debates. Discourse \& Society 11(3): 401-418, http://www.jstor.org/stable/42888323

Stewart, Patrick (2020). An expert in nonverbal communication watched the Trump-Biden debate with the sound turned down. The Conversation. Available at https://theconversation.com/an-expert-in-nonverbal-communication-watchedtemployinge-trump-biden-debate-with-the-sound-turned-down-heres-whathe-saw-148688 (Date of access: 10.10.21)

Tymbay, Alexey (2018). Communicative strategies of American politicians. RUDN Journal of Language Studies, Semiotics and Semantics 9(1): 105-123, https://doi.org/10.22363/2313-2299-2018-9-1-105-123

Van Dijk, Teun A. (2004). Text and context of parliamentary debates. Bayley, Paul, ed. Cross-cultural Perspective on Parliamentary Discourse. Amsterdam: John Benjamins, 339-372, https://doi.org/10.1075/dapsac.10.10dij

Van Dijk, Teun A. (2010). Political identities in parliamentary debates. Ilie, Cornelia, ed. European parliaments under scrutiny. Discourse strategies and interaction practices. Amsterdam: John Benjamins, 29-56, https://doi.org/10.1075/dapsac.38.03dij

Wilson, Deirdre, Sperber, Dan (2004). Relevance Theory. Horn, Laurence and Gregory Ward, eds. The Handbook of Pragmatics. Hoboken, New Jersey: Blackwell Publishing, 607-632, https://doi.org/10.1002/9780470756959.ch27

Wilson, Deirdre(2019). RelevanceTheory. OxfordResearchEncyclopediaofLinguistics. Oxford: Oxford University Press, https://doi.org/10.1093/acrefore/9780199384655.013.201 


\section{Prekidi kao odraz identiteta govornika u predsjedničkim debatama u SAD-u 2020. godine}

U radu se utvrđuje uloga prekida kao ključne komunikacijske strategije koja je obilježila predsjedničke debate u SAD-u 2020. godine. Pretpostavlja se da sudionici debata Donald Trump i Joseph Biden razumiju koliko bi se određeni tipovi jezičnog ponašanja mogli pokazati učinkovitima te namjerno koriste specifičnu komunikacijsku taktiku kako bi postigli bolje rezultate i pridobili podršku birača. Neke od strategija kojima su sudionici pribjegli bile su samo situacijske. Ipak, većina strategija identificiranih u ovom istraživanju podosta se ponavlja, što samo po sebi predstavlja stil debatiranja spomenutih sudionika. U istraživanju se također pretpostavlja da ponovljena kršenja ustaljenog procesa izmjene govornika, kao što su sustavni prekidi, mogu promijeniti javnu percepciju političareva komunikacijskog stila, koji se u radu promatra kao inherentnu komponentu političareva identiteta.

Keywords: speaker identity, presidential debates, interruptions as strategy, USA, 2020

Ključne riječi: identitet govornika, predsjedničke debate, prekidi kao strategije, SAD, 2020. 